\title{
Relationship of Personal Hygiene and BMI with OHI-S Scores among Primary School Children in a District in North India
}

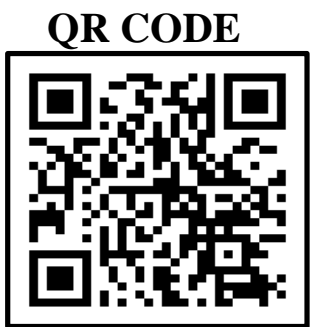

\section{FAHEEM BHATT¹ ${ }^{1}$ SHELLY SACHDEVA², KUSH PATHAK ${ }^{3}$ (D, VISHAL VASHISTH ${ }^{* 2}$, JYOTSNA RANI ${ }^{2}$}

INTRODUCTION: Malnutrition, among children can lead to various morbidities, and some of its consequences can be fatal.

AIM: To assess Hygiene with Nutrition \& Morbidity among school children in district Ambala, Haryana, India

MATERIALS AND METHOD: Data was collected through a health check-up program for primary school children studying in class I and class III (aged only between 6-9 years) using a pre-tested and pre-designed questionnaire, weighing scale, measuring tape and dental screening instruments. The investigators were duly standardized and concerned instruments were duly calibrated. No names and personal information was collected and before the student was sent for examination, his I-card was removed. Data cleaned and analyzed using SPSS version 22.0. Shapiro wilk-test for data normalcy revealed a parametric distribution of the data and hence, the student's t-test and multiple logistic regression were applied.

RESULTS: The study included 216 males and 106 females, and the maximum unfavourable score (unclean hands, feet and skin) was observed in $40.1 \%$ of the children. Difference between favourable and unfavourable scores with OHI-S $\leq 2$ was found to be $65.3 \%$ ( $\mathrm{p}=0.02$ ) and maximum students (68.9\%), reported having a good favourable OHI-S score ( $\mathrm{p}=0.01)$. It was observed that maximum males $(43.1 \%)$ and females (48.1\%) belonged to the "Normal" category of BMI, while lesser females $(6.7 \%)$ were overweight in comparison to their male counterparts. Multivariate logistic regression revealed that OHI$\mathrm{S}$ scores were significantly associated with BMI status $(\mathrm{p}=0.05)$ of the children, indicating that children with higher BMI scores have a tendency to have "fair" and "poor" OHI-S scores.

CONCLUSION: Based on the results, appropriate measures can be undertaken to ensure that schools as well as healthcare professionals undertake more stringent measures to educate parents, children as well as teachers regarding the relationship between poor oral health and increased BMI values.

KEYWORDS: Oral Hygiene, Body Mass Index (BMI), Malnutrition

\section{INTRODUCTION}

Undernutrition, has been described as a type of malnutrition directly related to inadequate dietary intake and infectious diseases and is influenced by three broad factors: food, health, and care. ${ }^{1}$ Among children, it is of concern as it can lead to various morbidities, and some of its consequences can be fatal.

The importance of school health has been acknowledged across countries since the beginning of 2oth century. As a matter of fact, health has been considered as one of the key factors determining the enrolment, performance and continuation of children in school. ${ }^{2}$ The 6.3 lakh (both primary and upper primary) schools of India serve as an important pedestal where education regarding important aspects of health (including) hygiene, environment and sanitation, as well as social customs, is being imbibed by the students. After parents, is the teacher, considered as the "guru", who acts as the guardian of the child in the "temple of learning" called school and play a significant role in the processes of disease prevention and specific protection among a community. ${ }^{3,4}$
An early identification of illnesses among children through periodic general and oral health screenings can prevent morbidities in them. ${ }^{5}$ Therefore, coordinated and regular activities pertaining to health and hygiene at school are needed, for better and health promoting school environment. It focuses mainly on nutritional disorders and personal hygiene which are important problems in India. School health programmes in India usually include general health, assessment of anaemia/nutritional status, visual acuity, hearing problems, dental check-up, common skin conditions, heart defects, physical disabilities, learning disorders, behavior problems, etc.

Due to the fact that both malnutrition and hygiene plays an important role in the development of good health, the present study was conducted to assess Hygiene with Nutrition \& Morbidity among school children in district Ambala, Haryana, India.

\section{MATERIALS AND METHODS}

After obtaining prior ethical clearance and permission from concerned authorities, a health check-up 
program for primary school children in government and semi-government schools studying in class I and class III (aged only between 6-9 years) was organized from October 2019 to February 2020. Data was collected using a pre-tested and pre-designed questionnaire (Cronbach alpha :0.77), weighing scale and measuring tape. The investigators were duly standardized and concerned instruments were duly calibrated.

General and systemic examinations of the students were conducted by the medical team, while dental examinations (OHI-S Index) were carried out by dental team. Data was entered into a pre-validated proforma by a standardized assistant who recorded the data as per the oral instructions of the investigators, thus preventing their distraction. No names and personal information were collected and before the student was sent for examination, his I-card was removed and investigators were strictly instructed not to ask the students for personal particulars, which was monitored by a member of the investigator team. Data thus collected was confidential, where it was cleaned and analyzed using suitable statistical tests with the help SPSS version 22.0. Shapiro wilk-test for data normalcy revealed a parametric distribution of the data and hence, the student's t-test and multiple logistic regression were applied.

\section{RESULTS}

The total students enrolled in the study were 322 , out of which, there were 216 males and 106 females. The general hygiene status of the students is depicted in table 1 and it was revealed that more students had favourable hygiene scores as compared to unfavourable hygiene scores. The maximum unfavourable score, 40.1\% was observed when the children had unclean hands, feet and skin. Most children reported having clean and combed hair $(78.3 \%, \mathrm{p}=0.05)$, followed by having clean uniforms (70.5\%). The difference between favourable and unfavourable scores with OHI$\mathrm{S} \leq 2$ was found to be $65.3 \%$, and the difference was found to be statistically significant.

Gender-wise distribution of BMI among the students is depicted in table 2 and the results indicated that maximum males (43.1\%) and females (48.1\%) belonged to the "Normal" category while lesser females $(6.7 \%)$ were overweight in comparison to their male counterparts.

Table 3. depicts the OHI-S scores of the students. Maximum students reported having a good favourable score $(68.9 \%)$, and the difference between the scores was found to be statistically significant $(\mathrm{p}=0.01)$. Unfortunately, $33.9 \%$ children belonging to the unfavourable hygiene group exhibited having a poor oral hygiene.

The analysis of the multivariate logistical regression is depicted in table 4. Its was observed that OHI-S scores were significantly associated with BMI status $(\mathrm{p}=0.05)$ of the children, indicating that children with higher BMI scores have a tendency to have "fair" and "poor" OHI-S scores.

\begin{tabular}{|c|c|c|c|c|c|c|c|}
\hline \multirow{2}{*}{$\begin{array}{l}\text { State of } \\
\text { Personal } \\
\text { Hygiene }\end{array}$} & \multicolumn{2}{|c|}{ Unfavourable Score } & \multicolumn{4}{|c|}{ Favourable Score } & \multirow[b]{2}{*}{$\mathrm{P}$} \\
\hline & Males & Females & Total & Males & Females & Total & \\
\hline $\begin{array}{c}\text { Combed } \\
\text { and Clean } \\
\text { hair }\end{array}$ & $16(7 \cdot 4)$ & $23(21.7)$ & $39(12.1)$ & $200(92.6)$ & $83(78.3)$ & $\begin{array}{c}283 \\
(87.9)\end{array}$ & 0.05 \\
\hline $\begin{array}{l}\text { Clean \& } \\
\text { Trimmed } \\
\text { Nails }\end{array}$ & $59(27 \cdot 3)$ & $38(15.4)$ & 97 (30.1) & $157(72.7)$ & $68(84.6)$ & $\begin{array}{c}225 \\
(69.9)\end{array}$ & NS \\
\hline $\begin{array}{c}\text { Clean } \\
\text { Uniform }\end{array}$ & $72(33 \cdot 3)$ & $23(21.7)$ & $95(29.5)$ & $144(66.7)$ & $83(78.3)$ & $\begin{array}{c}227 \\
(70.5)\end{array}$ & NS \\
\hline $\begin{array}{l}\text { Clean } \\
\text { Hands, } \\
\text { feet and } \\
\text { skin }\end{array}$ & $100(46.3)$ & $29(27.4)$ & $129(40.1)$ & $116(53.7)$ & $77(72.6)$ & $\begin{array}{c}193 \\
(59.9)\end{array}$ & NS \\
\hline $\begin{array}{c}\text { Clean/Oral } \\
\text { Cavity } \\
(\text { OHIS- } \\
\text { Score }<2 \text { ) }\end{array}$ & $106(49.1)$ & $6(5 \cdot 7)$ & $112(34 \cdot 7)$ & $110(50.9)$ & $100(94 \cdot 3)$ & $\begin{array}{c}210 \\
(65 \cdot 3)\end{array}$ & 0.02 \\
\hline
\end{tabular}

Table 1. Demographic Profiles, Favourable and Unfavourable Scores among the School Children 


\section{DISCUSSION}

The results of the present study indicate a significant association between BMI $(\mathrm{p}=\mathrm{0.05})$ and OHI-S scores of the children, and hence further strengthening data to the literature that oral health is indeed a gateway to one's general health. ${ }^{6}$

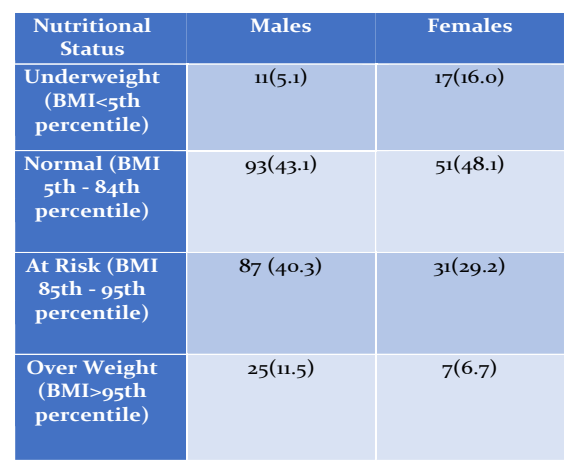

Table 2. Gender-wise distribution of BMI among the students

The results highlighted that most students had favourable hygiene scores as compared to unfavourable hygiene scores, and is it agreement to Deb S et al. ${ }^{4}$ Most children reported having clean and combed hair (78.3\%, $\mathrm{p}=0.05)$ and these results are in contraindication to Dongre AR et al. ${ }^{7}$, who reported the same only in $27.6 \%$ of the children. The difference between favourable and unfavourable scores with $\mathrm{OHI}-$ $\mathrm{S} \leq 2$ was found to be $65.3 \%$, and the difference was found to be statistically significant; thus indicating the need for incorporating oral health programmes among school children.

\begin{tabular}{c|c|c|c|}
$\begin{array}{c}\text { Total } \\
\text { Score } \\
\text { Obtained } \\
\text { (OHI-S }\end{array}$ & $\begin{array}{c}\text { Unfavourable } \\
\text { Score }\end{array}$ & $\begin{array}{c}\text { Favourable } \\
\text { Score }\end{array}$ & $\begin{array}{c}\mathbf{p} \\
\text { value }\end{array}$ \\
Index) & \multicolumn{3}{|c|}{} \\
\hline Good & $101(31.3)$ & $222(68.9)$ & 0.01 \\
Fair & $112(34.8)$ & $67(20.8)$ & \\
Poor & $99(33.9)$ & $33(10.3)$ & \\
\hline
\end{tabular}

Table 3. OHI-S scores of the students

Upon examination of BMI, it was observed that maximum males $(43.1 \%)$ and females $(48.1 \%)$ belonged to the "Normal" category while lesser females (6.7\%) were overweight in comparison to their male counterparts. This is stark contrast to Halder $\mathrm{S}$ et al. ${ }^{8}$, who reported normal scores in $10 \%$ males and $26 \%$ females. These differences can be related to the

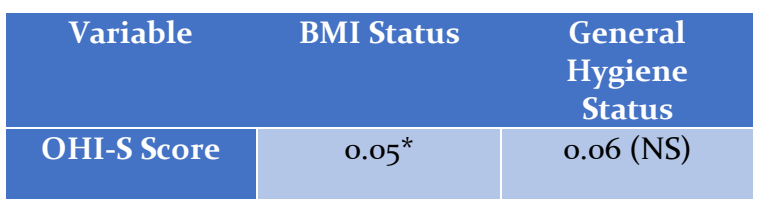

Table 4. Multivariate Logistical Regression between OHI-S, Nutritional Status and BMI

location of the schools, ease of access to junk food by the children and parental attitudes towards their child's nutrition. ${ }^{9}$

The results of the present study indicated that OHI-S scores were significantly associated with BMI status ( $\mathrm{p}=0.05)$ of the children which was an indication that children with higher BMI scores have a tendency to have "fair" and "poor" OHI-S scores and is in agreement to Haldar $\mathrm{S}$ et al. ${ }^{8}$, et al. who results indicated that BMI is positively associated with the deft, DMFT, and OHIS. In contrast, Rachmawati E et al. ${ }^{10}$ reported no clear relationship between oral hygiene index simplified with body mass index among children aged 6-8 years old in Bandung city, Indonesia.

The study is prone to the limitation of subjective bias in identifying favourable and unfavourable scores among the children, however, which was handled my standardizing all of the investigators. Also, no personal data of the children was collected and hence the confidentiality of the data was assured.

\section{CONCLUSION}

Based on the results of the present study, the results can be generalized for other school going children and appropriate measures can be undertaken to ensure that schools as well as healthcare professionals undertake more stringent measures to educate parents, children as well as teachers regarding the relationship between poor oral health and increased BMI values. All rural schools must mandatorily conduct dental and medical examinations of the children on a regular basis and any discrepancies must be raised by the teachers to the parents during the next parent-teacher conference.

\section{RESULTS}

1. Bagabaldo PAA, Bonifacio MRA, Layosa MAA, Cayetano AC, Africa LS. Relationship of Personal Hygiene Score with Sex, Nutritional Status, Morbidity, and Academic Grades Among Primary Grade School Children in a Public Elementary School in Pila, Laguna. Journal of Human Ecology 2020;9(1):33-46. 
2. Kishor J. National health programs of India. In: Kishor J, eds. A Book. 2nd ed. New Delhi: Century Publications; 2007: 441-7.

3. Varu RB. School Health Services in India: The social and economic context, Sage Publications Pvt. Ltd; 2008. p. 1-2.

4. Deb S, Dutta S, Aparajita Dasgupta1, Raghunath Misra. Relationship of Personal Hygiene with Nutrition and Morbidity Profile: A Study Among Primary School Children in South Kolkata. Indian Journal of Community Medicine 2010;35(2):280-4. https://doi.org/10.4103/o970-0218.66894

5. Panda P, Benjamin AI, Shavinder Singh, Zachariah P. Health status of school children in Ludhiana city. Indian J Community Med. 2000;25(4):150-5.

6. Hung M, Moffat R, Gill G, Lauren E, Ruiz-Negrón, B, Rosales $\mathrm{MN}$, et al. Oral health as a gateway to overall health and well-being: Surveillance of the geriatric population in the United States. Spec Care Dent. 2019;39:354-61. https://doi.org/10.1111/scd.12385
7. Dongre AR, Deshmukh PR, Garg BS. The impact of schoo health education programme on personal hygiene and related morbidities in tribal school children of Wardha district. Indian J Community Med. 2006;31:81-2.

8. Halder S, Kaul R, Angrish P, Saha S, Bhattacharya B, Mitra M. Association between Obesity and Oral Health Status in Schoolchildren: A Survey in Five Districts of West Bengal, India. Int J Clin Pediatr Dent. 2018;11(3):233-7. https://doi.org/10.5005/jp-journals10005-1517.

9. Datar A, Nicosia N. Junk Food in Schools and Childhood Obesity. J Policy Anal Manage. 2012 Spring;31(2):312-37. https://doi.org/10.1002/pam.21602. 10. Rachmawati E, Carolina DN, Susanto A, Mustika I, Primarti RS. Correlation between Oral Hygiene IndexSimplified (OHI-S) and Various Body Mass Index (BMI) Among 6-8 Years Old Children in Bandung City. International Journal of Science and Research (IJSR) 2018;7(1):490-3.

Cite this article as:

Bhatt F, Sachdeva S, Pathak K, Vashisth V, Rani J. Relationship of Personal Hygiene and BMI with OHI-S Scores among Primary School Children in a District in North India. Int Healthe Res J. 2021;5(6):ORi1-ORi4. https://doi.org/10.26440/IHRJ/0506.09451

\section{AUTHOR AFFILIATIONS: ${ }^{*}$ Corresponding Author)}

1. MDS (Public Health Dentistry), Ex-Consultant, Department of Dentistry, Alok Hospital, Upralsi, Dadri, GB Nagar, India

2. BDS, Consultant Dental Surgeons, Chandigarh, India

3. Reader, Department of Oral Pathology, Microbiology and Forensic Odontology, Maharishi Markandeshwar College of Dental Sciences and Research, M.M.U, Mullana-Ambala, Haryana, India, 133207 (https://orcid.org/oooo-0003-2801-938X) 